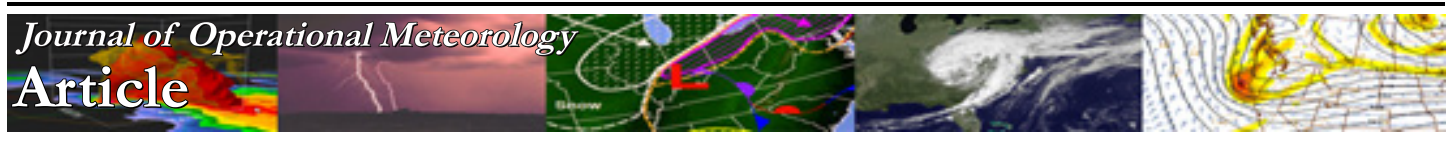

\title{
Impacts to Aviation Weather Center Operations Using Total Lightning Observations from the Pseudo-GLM
}

\author{
AMANDA TERBORG \\ NWS/NCEP Aviation Weather Center / Cooperative Institute for Meteorological Satellite Studies (CIMSS) - \\ Space Science and Engineering Center (SSEC), University of Wisconsin - Madison, Kansas City, Missouri \\ GEOFFREY T. STANO \\ NASA Short-term Prediction Research and Transition Center (SPoRT) / ENSCO, Inc., Huntsville, Alabama
}

(Manuscript received 23 March 2016; review completed 2 September 2016)

\begin{abstract}
The Aviation Weather Center (AWC) is responsible for delivering accurate, consistent, and timely weather information for safe and efficient flight across the United States airspace system along with international obligations. One of the key concerns for forecasters is the prediction and monitoring of convection which directly affects air routes as well as ground operations. Lightning observations are a vital component of available observations helping to confirm the presence of convection and verify forecasts. Up to this time the AWC has relied solely on ground-based cloud-to-ground only detection networks. With the upcoming launch of the Geostationary Lightning Mapper (GLM) aboard GOES-R, the AWC has the opportunity to expand the use of lightning observations by observing total lightning (i.e., the combination of both cloud-to-ground and intra-cloud observations). AWC and NASA's Short-term Prediction Research and Transition Center (SPoRT) have collaborated to assess a demonstration GLM product, the pseudo-GLM, derived from ground-based lightning mapping arrays. This collaboration has focused on the utility of using total lightning in aviation weather forecasting in preparation for the GLM instrument. This paper presents several small cases identified by forecasters using the pseudo-GLM data in operations and discusses the role of GLM data in the future.
\end{abstract}

\section{Introduction}

In 2013, approximately $58.3 \%$ of delay min in the National Airspace System (NAS) were attributed to weather (Bureau of Transportation Statistics 2015). These delays result in significant extra fuel costs (due to diverts), can necessitate extra flight and ramp crews along with equipment, often require passenger rebooking at the expense of the airlines, and impose costs on airline customers (i.e., shippers, etc.). In fact, the percentage of delay min listed above equated to roughly $\$ 4.7$ billion in extra costs for the airlines (Airlines for America 2016).

Weather delays can be caused by multiple hazards, including adverse winds (i.e., crosswinds or prevailing winds that prevent the use of several runways, compression winds on approach or take-off, etc.), low ceilings, winter weather (snow or freezing rain), and convection, though by in large the leading cause of weather-related delays comes from the latter. As convection carries the threat of severe turbulence, wind shear, icing, and lightning strikes, it is vital that both aircraft and ground operations crews avoid it. Depending on the severity and extent of the convection, significant rerouting, ground delays due to decreased traffic rates into and out of main terminals and safety concerns of ramp personnel can occur. In extreme cases, terminals or airspace may even be shut down.

It is the responsibility of the Federal Aviation Administration (FAA) to minimize the economic costs caused by these delays while also maintaining flight safety. For this reason NOAA's Aviation Weather Center (AWC) is tasked with issuing a variety of products, including the Convective SIGnificant METeorological (SIGMET) bulletin and National Aviation Meteorologist (NAM) briefings, designed to provide a short-term overview of convective activity expected to impact en route and terminal traffic in the 
NAS. Unlike a Weather Forecast Office, these products cover the entire conterminous United States (CONUS) as well as all of what the FAA designates 'Class A' airspace, or airspace between the surface and 60,000 feet (Prentice 2010). Additionally, where a Weather Forecast Office will only warn on convection determined to be severe (i.e., $1+$ in hail, $58+\mathrm{mph}$ wind gusts, or a tornado), the FAA requires the AWC to forecast for any convection, as even non-severe thunderstorms can cause a significant impact to the NAS.

As noted above, one of the safety risks associated with convection is lightning. A survey conducted by Boeing scientists (Sweers et al. 2012) determined that aircraft encountered most lightning strikes between 5,000 and 15,000 feet above ground level. This occurs in the climb and descent phases of flight, as pilots are required to navigate within clouds to both attain cruising altitude and maintain approach vectors. Although aircraft typically avoid the core of the convective and electrical activity, some precipitation was noted in $70 \%$ of strike cases. However, another $42 \%$ of the strike cases reported no thunderstorm in the immediate vicinity. Although no data were collected on the specific type of lightning encountered (intra-cloud or cloud-toground), the statistics and noted environmental characteristics at the time of the strikes suggests that intra-cloud activity is encountered far more often that cloud-to-ground.

This presents a unique challenge as the nature of intra-cloud strikes makes them very difficult to observe with current lightning detection networks. The National Lightning Detection Network (NLDN; Cummins et al. 1998, 1999), perhaps the most commonly utilized network over the CONUS, was designed to emphasize detection of cloud-to-ground flashes, but can observe some intra-cloud flashes and recent upgrades have improved this capability. Similarly, the Global Lightning Dataset (GLD360; Said et al. 2010) was also built to detect cloud-to-ground flashes across the globe with long range detection capabilities. This network is most capable of detecting cloud-to-ground flashes, but can occasionally pick up higher-powered intra-cloud flashes. Although observing intra-cloud flashes is important, only a few systems are available to observe total lightning. Two have been satellite-based. These were the Optical Transient Detector (Boccippio et al. 2001; Christian et al. 2003) and the Lightning Imaging Sensor
(LIS; Christian et al. 1999) aboard the Tropical Rainfall Measuring Mission (Simpson et al. 1988; Kummerow et al. 1998). Even when available, the low Earth orbit of these instruments meant that the short window of observations during an overpass ( $\sim 90 \mathrm{~s})$ and the temporal delays between revisiting a given location limited real-time applications. Beyond the satellite instrumentation, there are several short-ranged, groundbased lightning mapping arrays (LMAs; Rison et al. 1999; Thomas et al. 2004) across the United States that can observe total lightning (i.e., combined intra-cloud and cloud-to-ground lightning) with high detection efficiency. Thus, LMA-type observations that can observe the intra-cloud component of lightning are valuable for aviation forecasting. Although available continuously in near real-time, the LMAs have an operational range radius of $\sim 250 \mathrm{~km}$. This is beneficial at the Weather Forecast Office scale, but limited for AWC operations. The ground-based Earth Networks Total Lightning Network (Sloop et al. 2014) has been recently purchased by the National Weather Service and offers continuous lightning observations. Earth Networks' detection efficiency of intra-cloud lightning is much less than an LMA $(\sim 50 \%)$, but it is available across the CONUS. One drawback to Earth Networks is that its detection efficiency varies across CONUS.

One of the anticipated benefits of the next generation geostationary satellites, GOES-R/S/T, is the inclusion of the Geostationary Lightning Mapper (GLM; Christian et al. 1992, 2006; Goodman et al. 2013). With the ability to detect total lightning over most of the GOES field of view within $55^{\circ} \mathrm{N} / \mathrm{S}$, an average detection efficiency of no less than $70 \%$ over the field of view day or night, and continuous data with a $20 \mathrm{~s}$ latency, the GLM is expected to significantly improve the ability to advise the aviation community of lightning hazards. This will be especially important in data-sparse regions where radar observations are limited or unavailable. With the launch of GOES-R expected in 2016 there is a need for forecasters and aviation operators to become accustomed to these new data. To address this, NASA's Short-term Prediction Research and Transition center (SPoRT; Darden et al. 2002; Goodman et al. 2004; Jedlovec 2013) has developed a pseudo GLM (PGLM; Stano et al. 2010, 2011, 2012, 2014) product by utilizing the Lightning Mapping Array networks across the CONUS. This product has become the de facto training and demonstration GLM dataset for the GOES-R Proving Ground (Goodman et al. 2012). Since 2012, 
the PGLM has been evaluated each year at the AWC Summer Experiment, which is an annual experiment providing a pre-operational environment to deploy and demonstrate products and algorithms associated with weather-related aviation hazards. Additionally, forecasters become familiarized with next generation geostationary and polar satellite systems, with the PGLM serving as a tool within the GOES-R Proving Ground to demonstrate the impact of total lightning into AWC operations to prepare for GLM. The advantage of the AWC Summer Experiment is that it allows forecasters to evaluate experimental and demonstration products on systems that are used in operations. Also, because the future GLM data will not be used in isolation, forecasters can learn how to integrate the GLM with traditional satellite observations.

Section 2 provides a brief summary of the types of forecasts that lightning data have the most impact on as well as how the experimental data were evaluated. It is important to note that the Earth Networks observations were not evaluated in this paper. Although it has the ability to detect both CG and IC strikes (i.e., total lightning), it is not yet considered an operational source (i.e., no established operational long-term contract) with the National Weather Service, including the AWC. Therefore, only the Lightning Mapper Array (LMA) network was leveraged for total lightning observations.

Section 3 addresses the experimental PGLM product and how it is derived from the ground-based LMAs. Section 4 covers two cases where the PGLM data were evaluated for use in AWC operations. Each case explores how the use of total lightning observations versus the current $\mathrm{CG}$ observations may change the way in which each of these products are issued. The final section summarizes the results and provides a discussion for future activities.

\section{Relevant Aviation Weather Center operations using lightning data}

\section{a. AWC operations-Convective SIGMET}

As a requirement of the FAA, the AWC issues a variety of SIGMET bulletins for hazards expected to affect en route and terminal traffic (i.e., traffic around major airports) in the National Airspace System in the short-term. The most common of these bulletins is the Convective SIGMET (CSIG), issued for thunderstorms occurring over the CONUS. CSIGs are issued when one or more of the following conditions are expected to occur: 1) an area of active thunderstorms affecting at least 3000 square mi covering at least 40 percent of that area while also exhibiting any lightning, a satellite signature (such as a rapidly growing top) or strong radar reflectivity (typically echo tops to at least 20,000 feet), 2) a line of thunderstorms at least 60 mi long, with storms affecting at least 40 percent of that length, or 3 ) embedded thunderstorms or severe thunderstorms expected for $>30$ min during the valid period (regardless of the size of the area).

CSIGs are issued hourly at 55 min past the $\mathrm{h}$ over CONUS (Fig. 1a). CSIGs are valid for $2 \mathrm{~h}$ and superseded in the next hourly issuance. In addition, a 2-6 h outlook is provided at the end of these bulletins. CSIGs are often supplemented by Center Weather Service Units Center Weather Advisories. This is a similar two-h advisory issued for all weather hazards expected to affect traffic flow within the Air Route Traffic Control Center area (Fig. 1b). CSIGs are utilized by flight crews, in both general aviation and commercial airlines, to provide up-to-date advisories on convection that may impact terminal areas or jet routes within pre-established flight plans.

It is common practice when issuing these CSIGs to evaluate both radar echoes and lightning to determine if necessary conditions exist. Increasing lightning activity generally accompanies increasing vertical motion within the mixed phase region of a thunderstorm, which commonly indicates a strengthening updraft. For this reason, forecasters often use lightning to infer the likelihood of convective activity reaching and/or exceeding the CSIG thresholds as described above. The AWC does not issue products for the severity of a storm, which is the role of the local Weather Forecast Office.

Section 4a-b examine two cases that explored this relationship between the issuance of the CSIG and lightning activity, focusing on the impact that total lightning has on the forecast process beyond cloud-toground observations alone.

\section{b. AWC operations - National Aviation Meteorologist briefings}

The AWC works closely with the FAA to provide additional situation awareness on weather-related aviation hazards through briefings by the National Aviation Meteorologist (NAM). These meteorologists, 


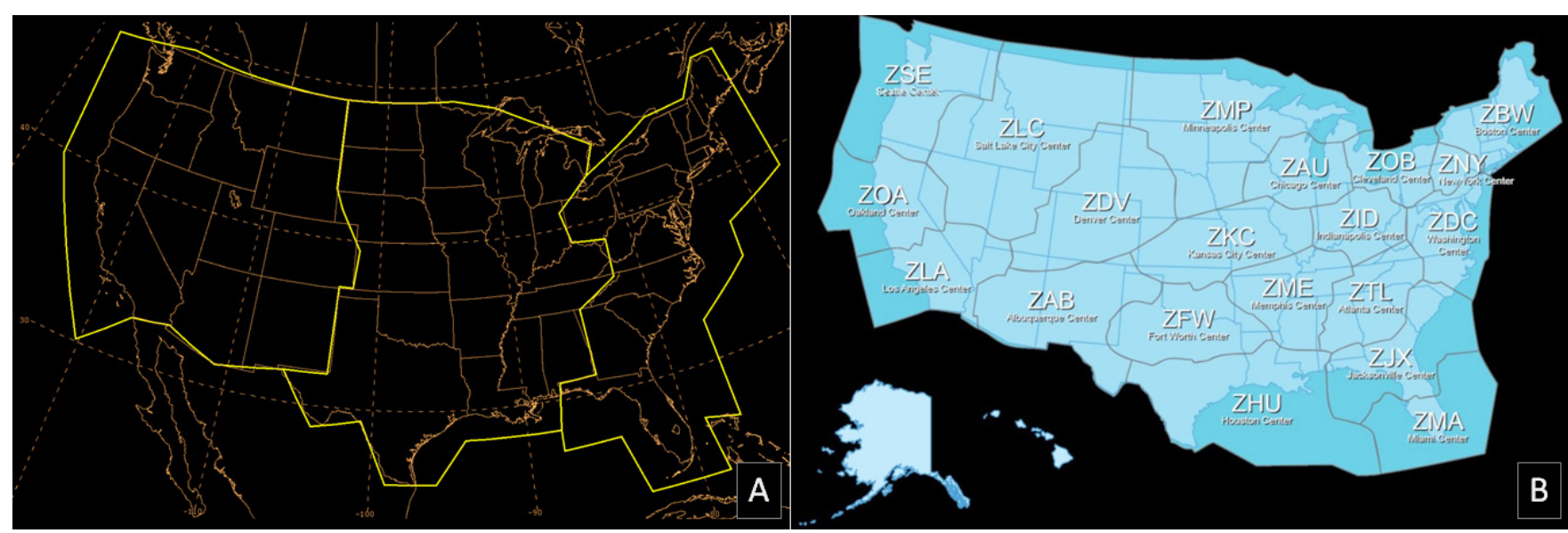

Figure 1. The three regions for convective significant meteorology statements (CSIG) for the United States (A) and the Air Route Traffic Control Center areas of responsibility (B).

posted at the Air Traffic Control Systems Command Center in Warrenton, Virginia, give real-time weather briefings to Traffic Flow Managers regarding hazards. Forecasts are predominantly issued for convection but also include, to a lesser extent, ceilings, winter weather, and winds that are expected to impact major airport terminals and flight routes. Traffic Flow Managers then use this information to build the necessary ground delay or ground stop programs each morning, or to come up with a list of potential divert routes in the case of an 'ad-hoc' plan. Specific programs are not issued for an ad-hoc plan; instead divert routes are utilized and adjusted as needed, typically during an event in which convection is expected to be sparse and low topped.

After traffic flow plans and programs have been established for the day, the NAMs transition to weather watch responsibilities. With large airports, such as Atlanta, where arrivals and departures per $\mathrm{h}$ number in the hundreds, it is vital that Traffic Flow Managers have real-time updates as convection begins to approach and impede this airspace and the associated jet routes. As previously mentioned, given the costs associated with delaying and cancelling flights, the airlines, and subsequently the FAA, strive to keep traffic rates up as long as possible while still maintaining the safety of flight. Traffic Flow Managers and Air Traffic Controllers slow or divert traffic when a radar echo top reaches the thirty thousand $\mathrm{ft}$ flight level (FL300) or if an echo exhibits increasing lightning activity (regardless of the height of the echo top). Section $4 b$ examines these rules in a case that occurred in the busy airspace over the Northeastern United States. Additionally, it explores the impact of total lightning on forecasts provided to traffic flow management, and subsequently, their reaction to developing convection.

\section{The Pseudo Geostationary Lightning Mapper mosaic}

As briefly described in Section 1, the PGLM product used in AWC Summer Experiment activities used total lightning observations from ground-based LMAs (Rison et al. 1999; Thomas et al. 2004) to generate an end product that could demonstrate GLM capabilities in an operational setting. The PGLM is not an exact replica for what the GLM instrument will observe due to differences between the ground-based LMAs and the GLM instrument, as described below. The groundbased LMAs are similar to a system developed by Lennon (1975) and described in more detail by Maier et al. (1995). Each LMA observes very high frequency electromagnetic radiation sources that are emitted over a broad range of frequencies by a developing lightning flash when charges are accelerated (Maggio et al. 2005). These LMA-detected sources are then mapped using a time of arrival technique (Proctor 1971, 1981; Lennon 1975; Maier et al. 1995). These very high frequency sources represent the stepped leader formation of lightning in the early stage of a lightning flash. Typically, this is before the visible return stroke, but very high frequency sources can be observed after a return stroke. The LMAs do provide three-dimensional observations (Boccippio et al. 2001; Koshak et al. 2004; Thomas et al. 2004) whereas the GLM does not. This technique gives LMAs the ability to observe the actual flash channel. Conversely, the GLM is an optical instrument that detects the visible light emitted by a flash and 
inherently has a much lower resolution. The PGLM product does not attempt to transform the very high frequency sources into an equivalent GLM optical event, preventing this from being an exact proxy. However, by doing this the PGLM can be run in real-time for any LMA network as the very high frequency sources are converted into flashes and then binned on an $8 \mathrm{~km}$ grid to simulate the GLM's resolution. This creates some differences between the PGLM and the GLM, but the general output (e.g., spatial extent and magnitude) is similar. With this flexibility to use any LMA in real-time, the PGLM serves as a powerful tool to educate forecasters on the capabilities of GLM and total lightning.

Figure 2 is a graphical representation of the construction of the PGLM product. Each LMA sensor observes raw LMA very high frequency sources (Fig. 2a). Using the raw sources, a flash creation algorithm (McCaul et al. 2005, 2009) is used to recombine the sources into discrete flashes (Fig. 2b). The McCaul et al. (2005) algorithm was selected for its rapid processing speed, which is vital to creating near real-time products, and favorable comparisons to other flash algorithms (e.g., Murphy 2006). Once the sources are grouped into flashes, another routine removes any flash with $<15$ sources. This is done based on communications with the Algorithm Working Group that indicate that these "small" flashes will likely not generate enough optical output to be observed by the GLM instrument. The remaining flashes are placed on an $8 \times 8 \mathrm{~km}$ grid to mimic the characteristics of the GLM observations (Fig. 2c). Note that the orange flash in the upper right is not included as it only has four sources. The number of flashes that pass through each grid box is summed with the rule that no flash can be counted more than once per grid box. The resulting flash extent density becomes the PGLM product (Fig. 2d) with red representing three flashes, orange representing two flashes, and blue representing one flash. This covers a two-min time period for each ground-based LMA.

The PGLM product was provided for display in the AWC's N-AWIPS (National Centers for Environmental PredictionAdvanced Weather Interactive Processing System - e.g., Fig. 3), so forecasters can evaluate these data side by side with existing operational and demonstration products during the Summer Experiment. For the AWC, all available LMAs were included in a single PGLM mosaic (Fig. 3) that updates every two $\min$ (i.e., the rate of the slowest LMA). For the AWC Summer Experiment
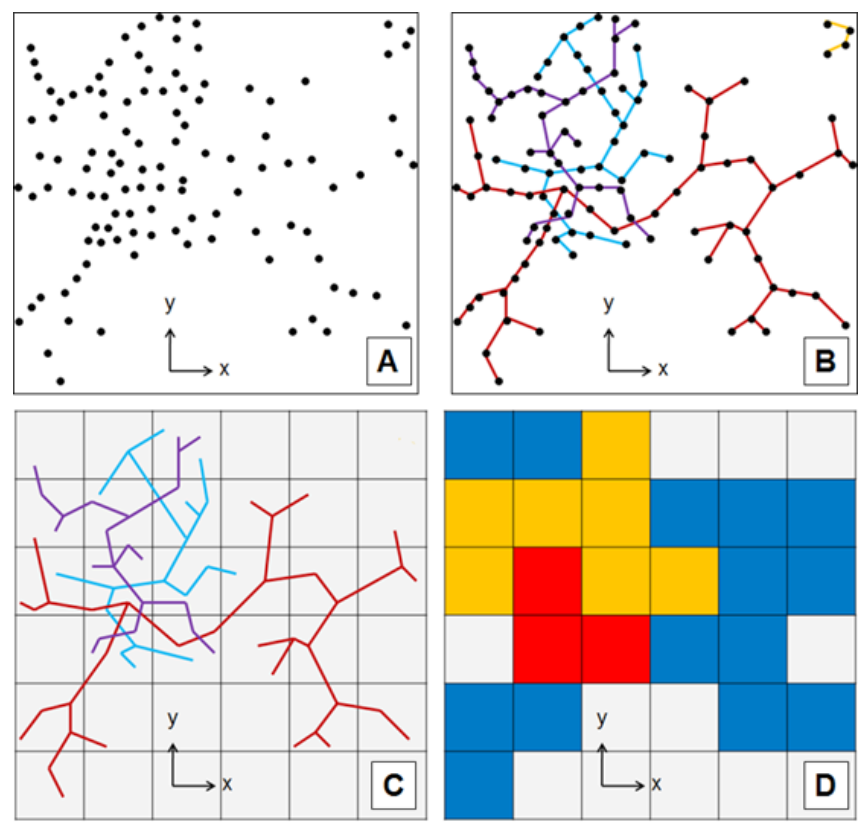

Figure 2. Development of the pseudo Geostationary Lightning Mapper product evaluated at the Aviation Weather Center showing the raw source input (A), linking sources to flashes via the flash algorithm (B), binning each flash onto a grid (C), and the resultant flash extent density (D). For the Aviation Weather Center, the flash extent density from all ground-based LMAs shows the number of flashes that occurred in each $8 \times 8 \mathrm{~km}$ grid box over a two min time period.

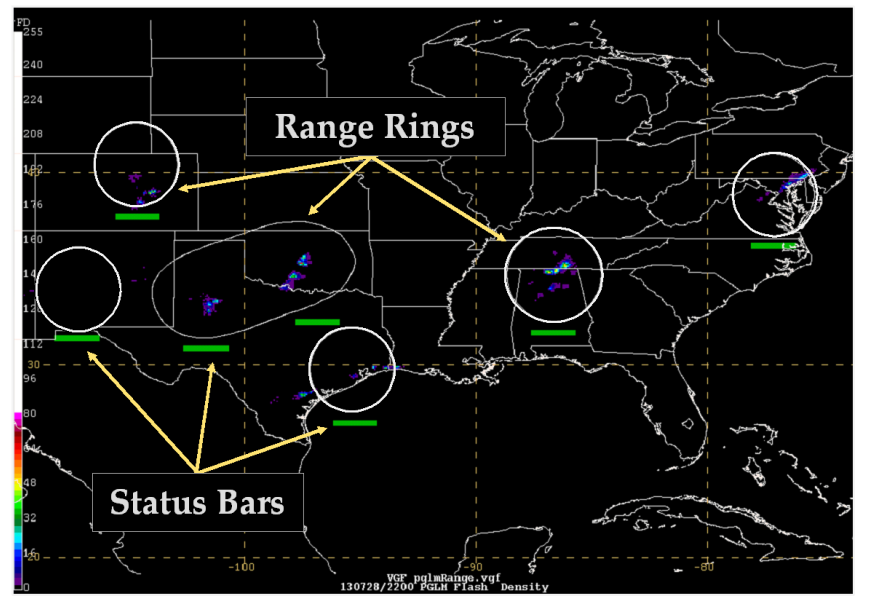

Figure 3. A sample of N-AWIPS display of the PGLM observations showing the range rings of the seven collaborating lightning mapping arrays evaluated at the Aviation Weather Center. The network status bars for each station are shown, which indicate if the given network is active and producing quality data. Note, the Norman and West Texas domains are combined, and the KSC domain was not operational during this time.

activities, NASA and university partners provide seven LMAs. The LMAs provide observations of total lightning only out to $250 \mathrm{~km}$ from the center of a network. This range limitation is due to the line of sight requirement to operate in the very high frequency portion of the electromagnetic spectrum. To allow 
forecasters to visualize these range limitations for each LMA domain, a range ring display component was developed for each LMA However, the range of the LMAs limits the PGLM, providing these demonstration data now allows forecasters to understand total lightning and the future GLM instrument.

\section{Operational cases}

a. Convective Significant Meteorological Statement (CSIG) - 30 June - 1 July 2012

As noted in section 2, Convective SIGMET bulletins are issued only if a specific set of conditions is met. These conditions guide how the polygon region is made, but it is a highly subjective process. The CSIG region issued is often characteristic of a forecaster's understanding of the convective environment and current observations. The following section outlines a case in Virginia from 2300 to 0130 UTC on 30 June to 1 July 2012, for which the utility of one such observation-the PGLM datawas explored in the issuance of a number of CSIGs. Specifically, it assesses how the addition of the total lightning observations from the GLM may impact the CSIG process and overall consistency of CSIG forecasting in the future.

A quasi-stationary front was draped across much of the Ohio Valley region throughout the event, bringing with it a very hot air mass characterized by surface temperatures in the mid-30s to nearly $40^{\circ} \mathrm{C}$ and dewpoints near $16^{\circ} \mathrm{C}$ by 1800 UTC on the 30th. This, along with Mixed-Layer CAPE values (in excess of $2000 \mathrm{~J} / \mathrm{kg}$ ) and steep low-level lapse rates made the environment favorable for convective growth. An abundance of tropospheric dry air and lack of stronger forcing kept the threat more isolated. This was reflected both in the Slight Risk indicated by the Storm Prediction Center's Day 1 outlook issued at 1300 UTC and the high confidence, sparse coverage included in the AWC's Collaborative Convective Forecast Product issued at $1500 \mathrm{UTC}$.

By 2123 UTC several isolated clusters of storms developed (Fig. 4a). These included clusters in southwestern Virginia that were outside the DCLMA domain and another cluster in north-central Virgina that pushed south-southeast through the state. Five min later at 2128 UTC the DCLMA observed flash extent densities of 3-10 flashes over two min in the north central storms (Fig. 4b). The corresponding NLDN
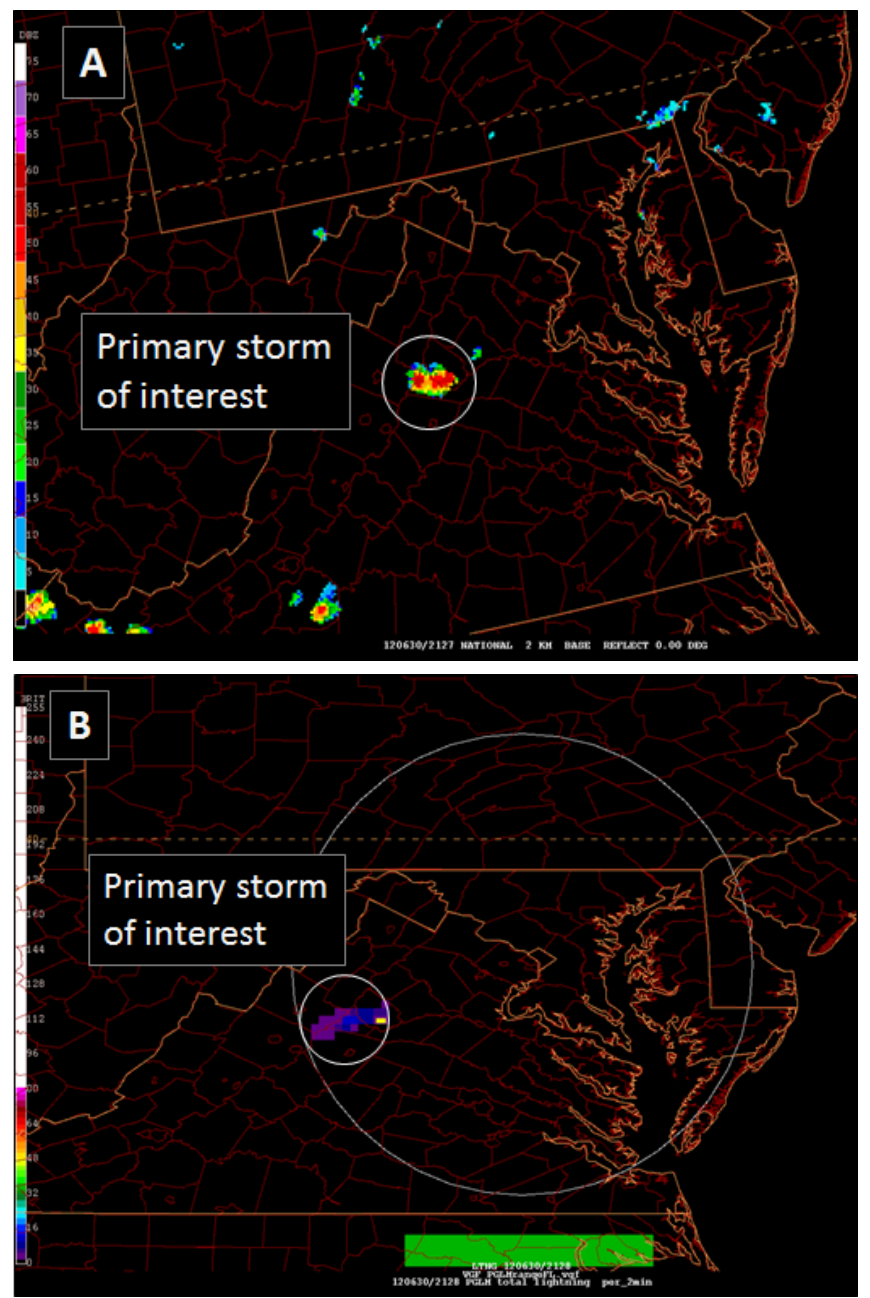

Figure 4. The N-AWIPS display of the composite radar reflectivity at 2123 UTC on 30 June 2012 (A) and the two min PGLM flash extent density five min later at 2128 UTC (B). The small white circle in both indicates the storm of interest. The large white circle in B is the domain of the DCLMA. Also, note that N-AWIPS uses different projections for each data type.

observations only had a single cloud-to-ground flash. These storms would persist for the next two $h$ and two separate CSIGs were issued at 2354 UTC (Fig. 5). Given the linear structure of the cells, both were classified as a line, with the north central storm's CSIG listed as 34E. After 0000 UTC those lines loosened into two areas of scattered severe cells, subsequently requiring the CSIG forecasters to change their issuance from linear to polygons. This change was reflected in the 0051 UTC CSIG issuance (Fig. 6). These polygons were reissued until the convection moved offshore and out of the domestic CSIG bounds.

This event did not directly impact any specific terminal, though caused numerous traffic flow disruptions with Washington, D.C.'s ARTCC region (ZDC). The CSIG issued for the main convective 


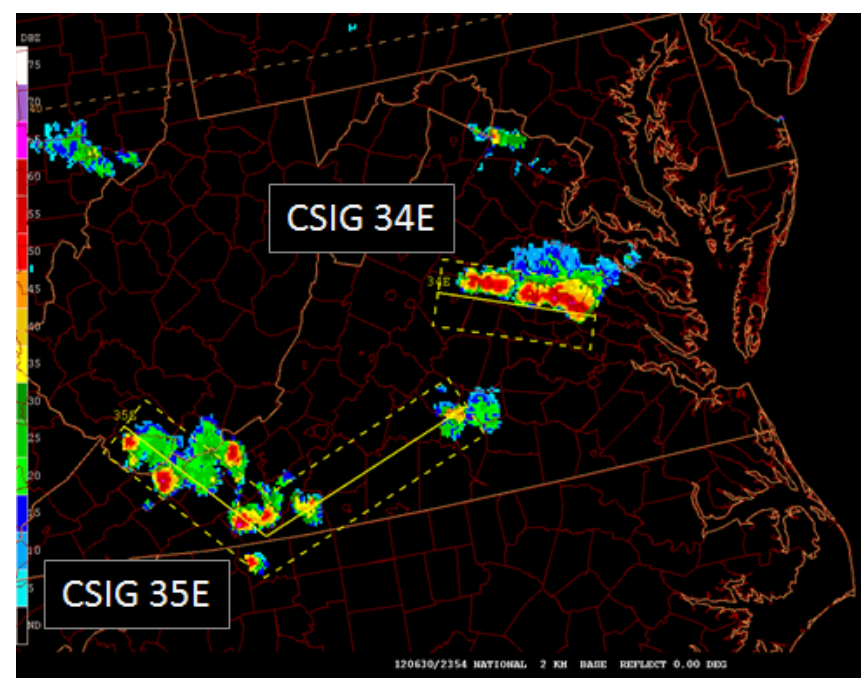

Figure 5. The radar composite reflectivity valid at 2354 UTC on 30 June 2012 and the corresponding linear Convective SIGMETs issued at the same time (dashed yellow boxes) as shown in N-AWIPS.

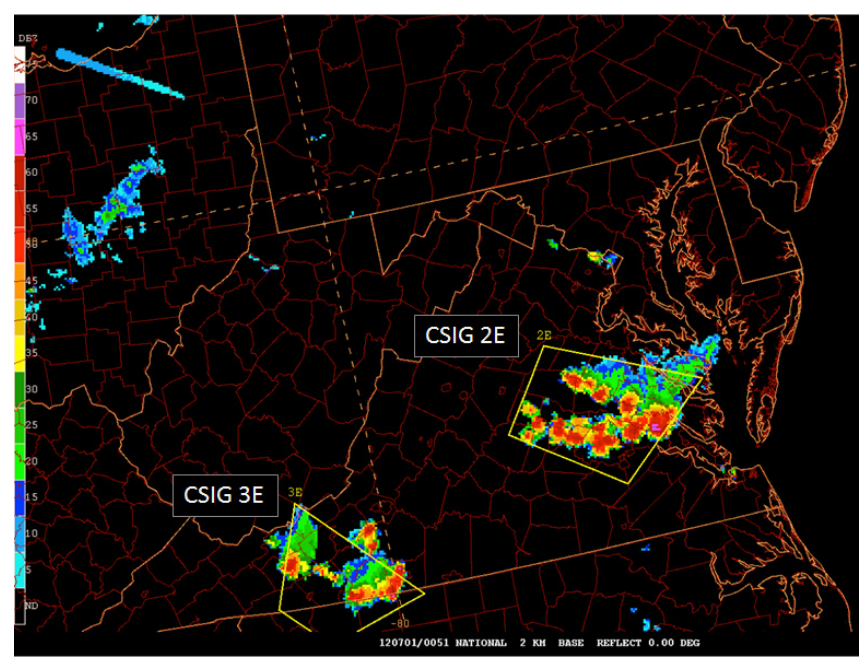

Figure 6. This is the same as Fig. 5, but now for 0051 UTC on 1 July 2012. Also note that the Convective SIGMETs (yellow polygons) have been converted from linear to polygon.

cluster in north central Virginia (34E and later 2E) prompted the closure of the Montebello and Gordonsville air routes. Traffic was diverted east and west of the convection, subsequently impacting arrivals into the southern gates of all three D.C. area airports (IAD, DCA, and BWI). Additionally, the diversions necessitated a reduction of traffic rates into the Northeast and caused delays at all three New York area terminals, as well as Philadelphia.

The PGLM data were examined in detail for this case, for the storm cluster in northern Virginia as it moved through the DCLMA domain. The PGLM correlated, as expected, to the radar reflectivities. Increased lightning activity corresponded to more intense cores. Additionally, one particular cell in the cluster showed a lightning jump (or significant increase in flash intensity) over a two-min period and a tornado was confirmed with that cell shortly thereafter. The lightning jump was meteorologically important, but not a concern for the AWC forecasters as the CSIG was already issued for these storms. However, there were also some very interesting observations of relevance to the CSIG forecasters that impacted the thinking process involved in issuing CSIGs.

The most significant of these was at 0022 UTC on 1 July (Fig. 7). The convection over east central Virginia was covered in CSIG 34E (Fig. 5). The tornado was on the ground at this time and the CSIG line covered the most likely areas of the convection and lightning activity as shown in the NLDN (Fig. 7). Just to the north of the activity in the region of stratiform rain (white boxes Fig. 7), outside the CSIG line boundaries (CSIG bounds Fig. 5), the PGLM indicated activity of roughly 6-10 flashes per two min where the NLDN had no cloud-to-ground flashes. CSIG forecasters typically issue the forecast based on echo tops and storms exhibiting any cloud-to-ground lightning activity. These observed features are most concentrated on the core of the storm. Therefore, the forecaster's CSIG is mostly likely to not extend beyond these observed features. With the PGLM total lightning flash extent density, and future GLM observations, it is clear that lightning is extending well into the stratiform region. This raised the question of whether or not a CSIG should be extended to account for these observations as this could increase the chance of the aircraft being struck by lightning, requiring a maintenance check, or encountering turbulence from the main storm core. In this case, the storms were isolated and the extra area of the CSIG was unlikely to have altered aircraft reroutes that had already occurred. The concern is greater if the expansion of the CSIG area into the stratiform region were more widespread. If this were the case, the extension of the CSIG could significantly impact traffic flow.

Another observation garnered from the exploration of the PGLM data was in the initial development of the storms shortly before 2100 UTC and the initial issuance of the CSIG. There are times in which a single cell may be borderline based on the requirements of the bulletin. Radar reflectivities at 2053 UTC (Fig. 8) and before (not shown) were $\sim 30-35 \mathrm{dBZ}$, but there was very little lightning activity, and echo tops had not quite reached the 20,000 feet mark (not shown). As mentioned in 


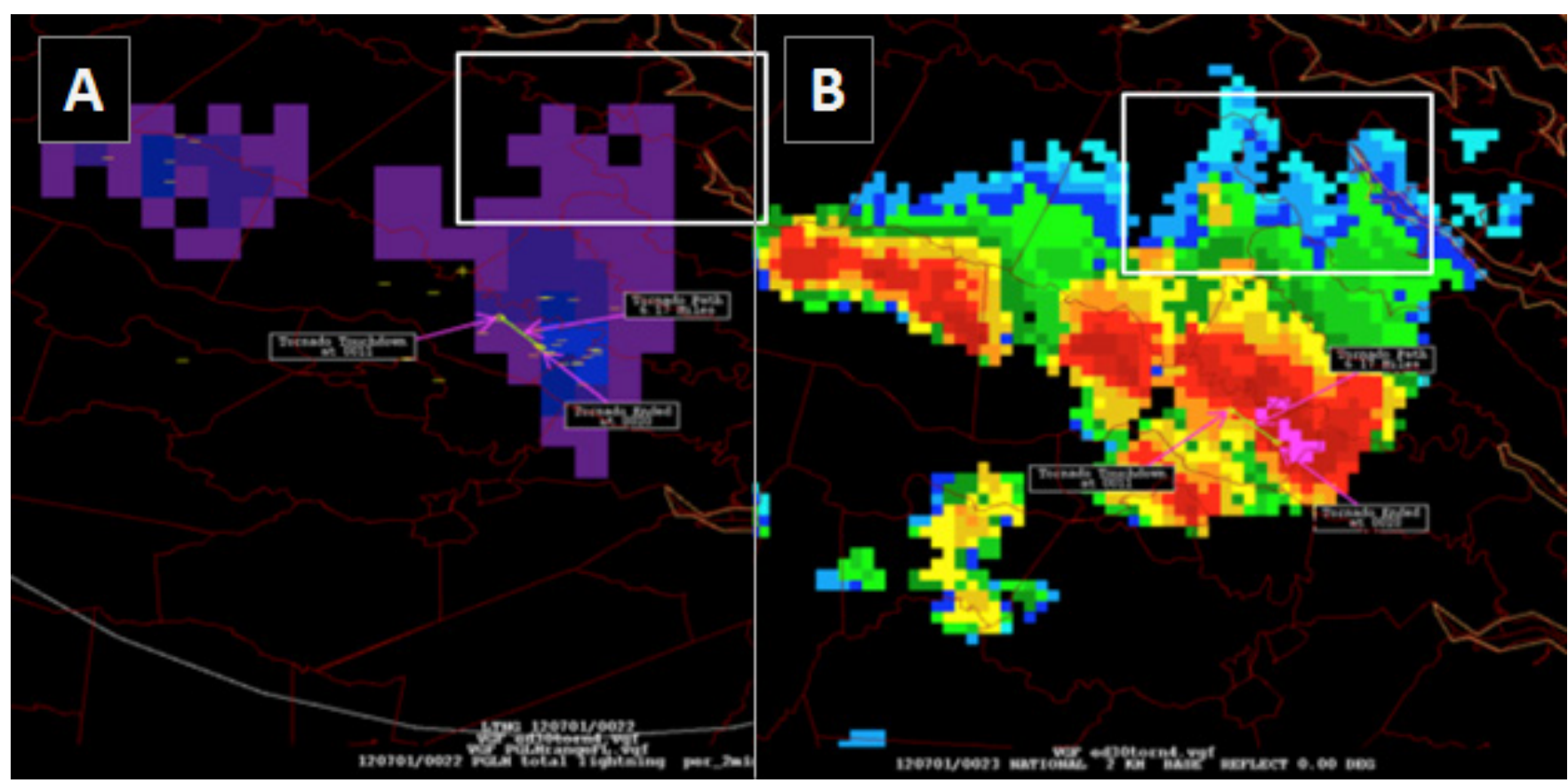

Figure 7. A zoomed-in view of the storms in north central Virginia with the active Convective SIGMET at 0022 UTC on 1 July 2012 . The two min PGLM flash extent density (A) and composite radar reflectivity (B) are shown with the trailing stratiform region highlighted by the white box. Note the flash extent density observing lightning several tens of kilometers behind the main convective core. This is well to the north and east of the established CISG as shown in Fig. 5.

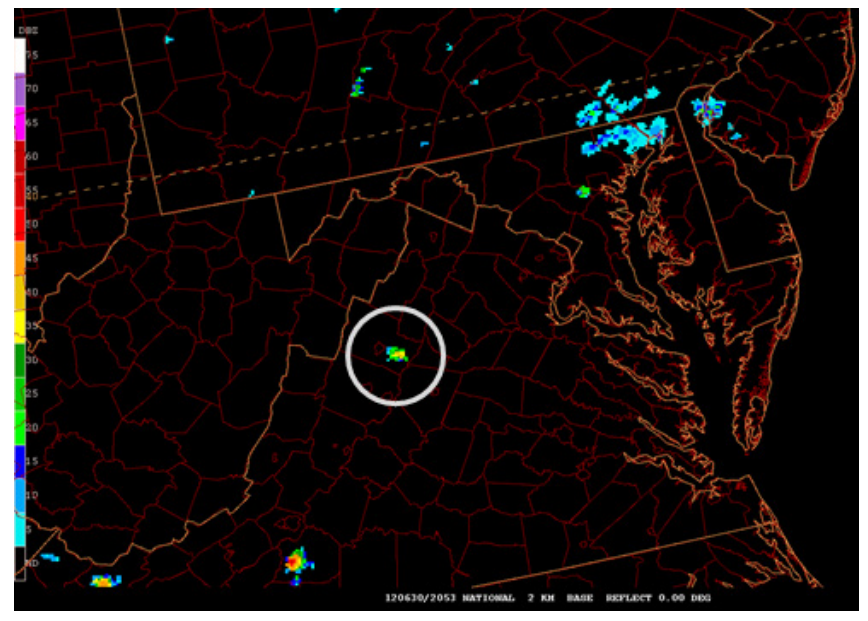

Figure 8. Composite radar reflectivity in N-AWIPS at 2053 UTC on 30 June 2012 with the storm of interest circled.

section 2a, CSIGs are issued at 55 past the h. In this case, the forecaster declined to issue a CSIG given the marginal thresholds. The PGLM data could not help in this particular case as the storm was right on the edge of the DCLMA's detection capabilities. In the GLM era, these domain issues will not exist. Discussions with forecasters noted that had these data been available and showed lightning activity, the decision may have been changed to issue the CSIG earlier. In this case, the storm cluster would reach CSIG criteria at 2115 UTC and would be reflected in the 2155 CSIG issuance.
The PGLM was also useful in the initial stages of convection in north central Virginia, where storms had begun to develop by 2123 UTC (Fig. 4a). In this case, the PGLM data (Fig. 4b) corresponded well to the radar reflectivity and observed a flash extent density of 2-10 flashes shortly at 2128 UTC (Fig. 4b). The more important item is the westward extent of the flash extent density. Total lightning PGLM observations were persistently extending westward beyond the core convection. This could simply indicate long flashes in a blown off anvil or indicate a new storm core is developing, but not yet observed on radar. The $8 \mathrm{~km}$ resolution of the PGLM, and the future GLM, makes it difficult to determine if the lightning is connected to the existing convection or part of a new core. Even with the uncertainty, this alerts the CSIG forecaster that there may be more activity than is currently observed on radar. This is confirmed at 2146 UTC (Fig. 9) when the composite radar reflectivity image identifies a new 35 $\mathrm{dBZ}$ storm core just to the west of the main convection, where the PGLM was observing flashes. It also should be noted that in this and all above described cases, satellite data were also utilized. Various features in visible satellite imagery, such as boundaries or convective outflow, provide additional situational awareness of the convective environment. Therefore it is important that forecasters utilize the PGLM data 


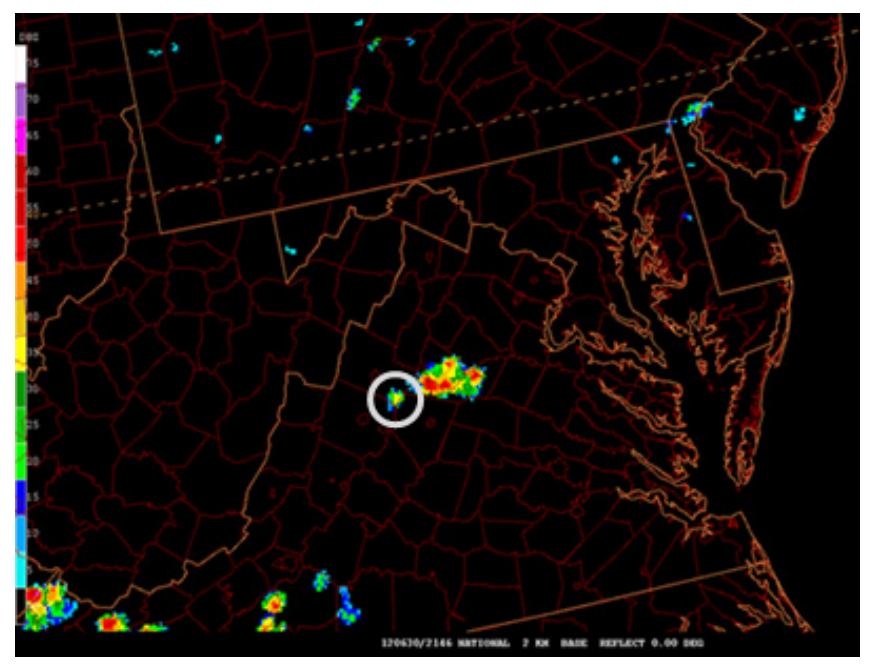

Figure 9. Composite radar reflectivity in N-AWIPS at 2146 UTC on 30 June 2012.

along with radar, satellite, and other observations and not as a standalone.

This section shows just two ways in which the future GOES-R GLM observations may impact CSIG operations. This includes expanding CSIGS further into the stratiform region based on the spatial extent of lightning flashes and identifying potential new convection before it is observed on radar. These could be major impacts to CSIGs, whose issuance is a tricky proposition given forecaster subjectivity despite the set requirements by the FAA. Additional observations like the GLM will make this even more challenging, as it is another dataset to monitor. The initial work here has shown the potential benefits. The AWC will perform additional evaluations of GLM data in observations to further explore this impact and the possible adjustments to CSIG issuances.

\section{b. National Aviation Meteorologist briefing - 6 September 2014}

Lightning strikes are hazardous to aircraft and often the onset of these strikes is what necessitates rerouting aircraft around a cell or convective complex. Furthermore, the location of the lightning strikes is used to determine a safe distance at which to circumvent the convection, generally ranging from 25-50 $\mathrm{mi}(40-80 \mathrm{~km})$, depending on the airline. At this nowcasting or tactical level of flight route management, the National Aviation Meteorologist is responsible for briefing traffic flow managers on potential weather impacts to air traffic. The example from 6 September 2014 in Maryland, below, explores the potential effect of total lightning activity on the National Aviation Meteorologist responsibilities, and subsequently the reaction of traffic flow managers.

This event took place within Washington Center's Air Route Traffic Control Center region and included the airspace surrounding Dulles (IAH), Reagan National (DCA), and Baltimore (BWI) airports. Additionally, it fell inside the domain of the DCLMA. It occurred between 1800 and 0000 UTC, with the greatest impact between 1930 and 0000 UTC in which the bulk of transcontinental traffic departs from the Northeast airports to West destinations.

As is typical on a late summer afternoon, a weak cold frontal boundary set up across the Northeast, edging slowly southeastward. With surface temperatures around $30^{\circ} \mathrm{C}$ and dewpoints around $22^{\circ} \mathrm{C}$ across the region, scattered convection quickly initiated ahead of the front after 1630 UTC. The first scattered cells entered the DCLMA domain shortly after 1900 UTC (radar not shown) and were already showing multiple cloud-to-ground strikes at this time. The PGLM also indicated flashes occurring in this convective area, with 20+ flashes per two min associated with the strongest cell on the MarylandPennsylvania border (Fig. 10).

AWC forecasters use the Aircraft Situation to Display Industry (ASDI) flight tracking data to help monitor air traffic within their forecast regions. Additionally, air traffic approaching or departing an airport is assigned to specific gates roughly $50 \mathrm{mi}$ from the airport as they depart the Terminal Radar Control airspace. These gates and the associated flight paths are rigidly established to ensure aircraft traveling on opposite vectors do not encroach on one another. Though slight variants exist depending on surface winds and runway orientations of specific airports, departing flights are arranged along the cardinal directions (north, east, south, and west) while arriving flights are offset by 45 degrees (northeast, southeast, southwest, and northeast). Convection in the vicinity of these gates can partially or completely close the approach/departure route, forcing aircraft to either hold, reduce the amount of aircraft using the gate, or divert to a different approach, which can lead to delays as ground operations may have to reconfigure for a less favorable runway configuration.

The ASDI showed flight traffic into and out of DCA and IAD remained largely unaffected at 1908 UTC (Fig. 10), with the exception of a few minor reroutes for the north gates. Conversely, both the east and north 


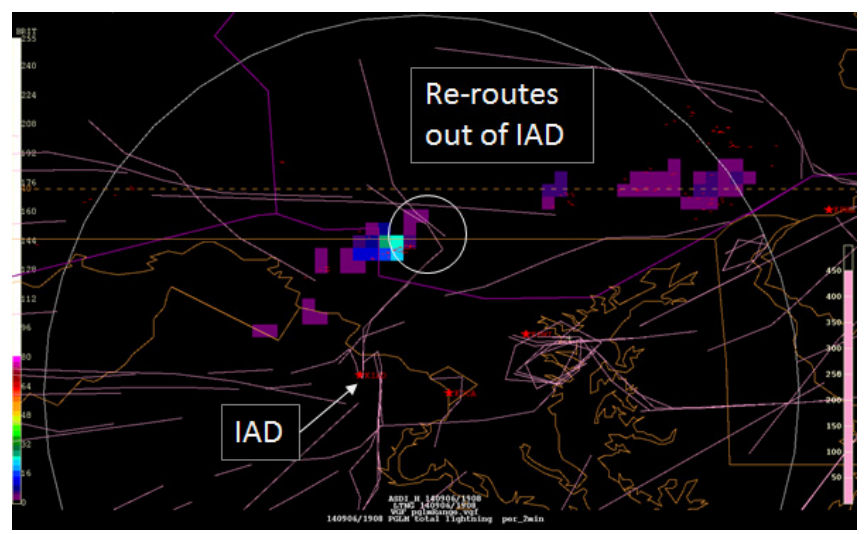

Figure 10. The two min PGLM mosaic flash extent density (shaded grid boxes) from the Washington, D.C. LMA at 1908 UTC on 6 September 2014 and corresponding aircraft flight tracks (pink lines). The small circle shows where flights are being re-routed east of storms north of IAD. The larger circle is the operational extent of the Washington, D.C. LMA, whereas the red dashes indicate the locations of NLDN detected cloud-to-ground strikes over the past five min.

gates for BWI were affected and arrivals were being directed into a holding pattern. This allowed time for delayed departures to get out and open up ramp space at the terminal for incoming arrivals.

By 1928 UTC radar observations (Fig. 11) showed that the scattered cells continued to maintain a moderate strength, but lost their original porosity (i.e., allowing aircraft to fly through gaps in the storms), morphing into a convective cluster. The strongest cluster was located in southeast Pennsylvania, and while many cloud-to-ground strikes were detected (Fig. 11), the storm's location at the far edge of the DCLMA domain kept the full extent of the total lightning flashes from being detected. While the storm was at the limit of the DCLMA's range, the PGLM observations still show a wide area of coverage for these storms that extends beyond the cloud-to-ground strikes alone. This general trend can be implied for the cluster of cloud-to-ground strikes just outside of the DCLMA range. Further to the west and south, the clusters continued to show $20+$ flashes per two min, particularly along the central Maryland/Pennsylvania border (Fig. 11).

Departures and arrivals out of all three airports' north gates continued to be impacted. However, the radar indicated an opening near an area of stratiform precipitation in the clusters of cells in western Maryland (near the West Virginia border) with no cloud-to-ground strikes detected in the immediate vicinity. After shifting all west gate traffic to the southwest, this allowed all north gate traffic to "shoot the gap" (i.e., attempt to maneuver between the convective cells in Maryland
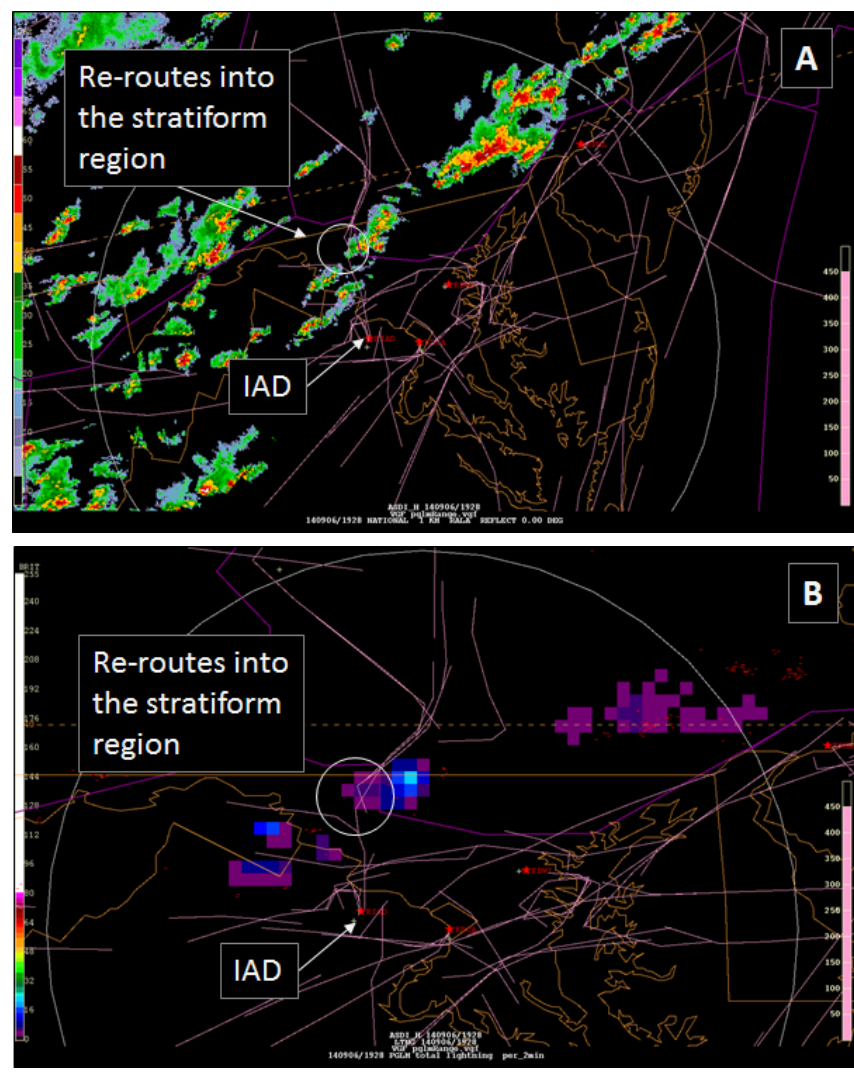

Figure 11. This shows the scene $20 \mathrm{~min}$ after Fig. 10. The composite radar reflectivity (A) surrounding Washington, D.C. at 1928 UTC on 6 September 2014 is compared to the corresponding PGLM two min flash extent density (B). Both figures show the DCLMA domain (large white circle) and the small circle highlights the region where aircraft (pink lines) departing out of the northern gates of IAD are traveling through a region of stratiform precipitation but active lightning.

and eastern West Virginia). However, in the same gap, the PGLM from the DCLMA was detecting lightning activity of 6-10 flashes every two min. Whereas this was comparatively minor activity to a severe cell, any type of lightning can cause damage to aircraft equipment, either from the direct strike or from the aircraft encountering turbulence.

This case showed that the National Aviation Meteorologist briefers, who did not have access to the PGLM at this time, were indeed routing aircraft away from the greatest threat. In the GOES-R and GLM era, the National Aviation Meteorologists will be able to use the total lightning data to their advantage in similar situations. In an event with widely scattered convection as described above, the National Aviation Meteorologist on duty would have been in constant communication with the traffic flow managers regarding the location, strength, and porosity of the activity. When the gap in the cells became evident in the 1928 UTC radar scan, the 
National Aviation Meteorologists would immediately take note of the total lightning activity from the GLM and advise against using that particular reroute.

\section{Discussion and conclusions}

NOAA's AWC and NASA's SPoRT center have been collaborating since mid-2012 to evaluate the use of total lightning (intra-cloud and cloud-to-ground observations) in AWC operations. This effort has been part of the GOES-R Proving Ground and relies on total lightning observations from seven collaborative, ground-based lightning mapping arrays (LMAs). The raw LMA data are processed into the pseudogeostationary lightning mapper (PGLM) product and displayed in the AWC operational system, N-AWIPS, in order to demonstrate potential observations from the future GOES-R GLM instrument. This has been supported through site visits to AWC to understand the forecast issues faced by AWC and with the development of AWC-specific training on the use of these data, with an end goal of preparing forecasters now for the GLM instrument. Although the ground-based LMAs are short-ranged, they provide similar observations to the GLM. Additionally, as the LMAs are predominantly in locations with good radar coverage, forecasters have the opportunity to inter-compare total lightning with the more familiar radar data. This is vitally important so that forecasters develop the physical understand of what total lightning observations provide so that when the GLM is launched, forecasters will be confident in using these observations in data-sparse regions, such as trans-oceanic routes.

Unlike a local Weather Forecast Office that has demonstrated the use of total lightning in severe weather and safety operations, the AWC operational requirements are different. These include:

- forecasting the timing and location of any convective activity, particularly with the collaborative convective forecast product, which is now transitioned to the Collaborative Aviation Weather Statement (started in March 2015);

- once convection is active, monitoring the evolution of convection; and

- providing National Aviation Meteorologist briefings and issuing convective significant meteorological statements (CSIGs) for air routing purposes.

Each of these efforts have been identified as potential uses of total lightning observations, with examples given in the two examples in the previous section. The total lightning observations can support AWC forecasts by:

- updating at a sub-radar volume scan temporal frequency (i.e., two min for the PGLM);

- providing more information than cloud-to-ground observations alone and typically preceding the initial cloud-to-ground strike in a storm;

- providing information on the intensity of storm updrafts given the link between total lightning production and the strength and volume of the storm updraft; and

- providing the spatial extent of lightning, especially as it extends into the stratiform region of storms.

The AWC forecasters have noted several successes of these data in the early stages of the AWC-SPoRT collaboration. The most commonly noted use is the spatial extent of total lightning. Discussions with the AWC have indicated that the LMA-based PGLM has demonstrated that CSIGs and National Aviation Meteorologist briefings may likely expand their spatial coverage because of these observations. This trend will continue to be monitored with the PGLM now and in the future once the GLM instrument is launched. The PGLM total lightning observations have also benefitted forecasters observing convection that may be intensifying. Because of the high temporal frequency and the relation of total lightning to storm updraft strength and volume, PGLM observations can identify new convective cells that are developing. This identification can be used to issue or modify CSIG bulletins, such as in the case of the cap breaking in a region, and also in tactical National Aviation Meteorologist briefings to alert aircraft to not fly over developing convection that may not be readily apparent on radar. The examples also showed that impacts to forecast decision making are possible even with low levels of lightning activity, reinforcing that any convection and not just severe convection, as defined by the National Weather Service, is of great importance to AWC forecasters.

The AWC-SPoRT collaboration will continue with updates to the PGLM display in N-AWIPS ahead of the final transition to AWIPS II. In the initial transition, the PGLM data have been difficult to integrate with other datasets on N-AWIPS. SPoRT, based on this feedback, has transitioned a modified product in 2015 to correct 
this. Additionally, AWC and SPoRT will continue to evaluate the product to identify opportunities for developing aviation specific tools, products, and training. Furthermore, new LMA networks are coming online in locations of strategic interest to the AWC (i.e., Atlanta, Georgia and Toronto, Ontario) that will continue to expand collaborations.

Acknowledgments. The authors would like to thank the GOES-R Proving Ground for funding these total lightning efforts. Additionally, the authors wish to thank the Aviation Weather Center forecasters, particularly Ed Holicky, for their invaluable feedback and case examples used in the evaluation and with this paper.

\section{REFERENCES}

Airlines for America, 2016: "Per-Minute Cost of Delays to U.S. Airlines.” N.p., 16 Jan. 2016. Web. 5 March 2016. Research and Innovative Technology Administration: Airline On-Time Statistics and Delay Causes. Bureau of Transportation Statistics. n.d. [Available online at http://www.transtats.bts.gov/OT Delay/OTDelayCause1.asp?pn=1]

Boccippio, D. J., K. L. Cummins, H. J. Christian, and S. J. Goodman, 2001: Combined satellite- and surface-based estimation of the intracloud-cloud-to-ground lightning ratio over the continental United States. Mon. Wea. Rev., 129, 108-122, CrossRef.

Research and Innovative Technology Administration: Airline On-Time Statistics and Delay Causes. Bureau of Transportation Statistics. n.d. http://www.transtats.bts. gov/OT_Delay/OT_DelayCause1.asp?pn=1

Bureau of Transportation Statistics, 2015: "Data and Statistics" Data and Statistics $\mid$ Bureau of Transportation Statistics. N.p., n.d. Web. 5 May 2015, [Available online at http://airlines.org/data/per-minute-cost-of-delays-tou-s-airlines/]

Christian, H. J., 1999: Optical detection of lightning from space. Proceedings of the 11th International Conf. on Atmospheric Electricity, Guntersville, Alabama, June 7-11, 715-718.

Christian, H. J.__ 2006: Geostationary Lightning Mapper (GLM). 12th Conf. on Aviation Range and Aerospace Meteorology / 2nd Conf. on Meteorological Applications of Lightning Data, Amer. Meteor. Soc., Atlanta, GA, J2.3, [Available online at https://ams.confex.com/ams/ Annual2006/techprogram/paper_105471.htm]

Christian, H. J. _ R. J. Blakeslee, and S. J. Goodman, 1992: Lightning Imaging Sensor for the Earth Observing
System. Tech. Rep. NASA TM-4350, NASA, Washington, D.C. [Available online at https://ntrs.nasa.gov/search. jsp? $\mathrm{R}=19920010794$ ]

Christian, H. J._, and Coauthors, 2003: Global frequency and distribution of lightning as observed from space by the Optical Transient Detector. $J$. Geophys. Res., 108(D1), 4005, CrossRef.

Cummins, K. L., M. J. Murphy, E. A. Bardo, W. L. Hiscox, R. B. Pyle, and A. E. Pifer, 1998: A combined TOA/MDF technology upgrade of the U.S. National Lightning Detection Network. $J$. Geophys. Res., 103, 9035-9044, CrossRef.

Cummins, K. L., R. B. Pyle, and G. Fournier, 1999: An integrated American lightning detection network, 11th International Conference on Atmospheric Electricity, 7-11 Jun 99, 218-221.

Darden, C. B., B. Carroll, S. Goodman, G. Jedlovec, and B. Lapenta, 2002: Bridging the gap between research and operations in the National Weather Service: Collaborative activities among the Huntsville meteorological Community. NOAA Tech. Memo. NWS SR-222, NWS Southern Region, Fort Worth, TX, 29 pp. [Available online at https://www.weather.gov/media/hun/research/ NASA-NWS TechMemo.pdf]

Goodman, S. J., W. M. Lapenta, G. J. Jedlovec, J. C. Dodge, and J. T. Bradshaw, 2004: The NASA Short-term Prediction Research and Transition (SPoRT) Center: A collaborative model for accelerating research into operations. Preprints, 20th Int. Conf. on Interactive Information Processing Systems (IIPS) for Meteorology, Oceanography, and Hydrology, Seattle, WA, Amer. Meteor. Soc., P1.34. [Available online at https://ams.confex.com/ams/84Annual/ t e chprogram/paper $70210 . \mathrm{h} \mathrm{t} \mathrm{m}$ ams.confex.com/ams/pdfpapers/70210.pdf]

Goodman, S. J._, and Coauthors, 2012: The GOES-R Proving Ground: Accelerating user readiness for the next-generation geostationary environmental satellite system. Bull. Amer. Meteor. Soc., 93, 1029-1040, CrossRef.

Goodman, S. J._, and Coauthors, 2013: The GOES-R Geostationary Lightning Mapper (GLM). Atmos.Res., 126, 34-49, CrossRef.

Jedlovec, G., 2013: Transitioning Research Satellite Data to the Operational Weather Community: The SPoRT Paradigm. IEEE Geosci. \& Remote Sens. Mag., 62-66, CrossRef.

Koshak, W. J., and Coauthors, 2004: North Alabama Lightning Mapping Array (LMA): VHF source retrieval algorithm and error analysis. J. Atmos. Ocean Tech., 21, 543-558, CrossRef.

Kummerow, C., W. Barnes, T. Kozu, J. Shiue, and J. Simpson, 1998. The Tropical Rainfall Measuring Mission (TRMM) sensor package. J. Atmos. Ocean 
Tech., Vol. 15, 809-817, CrossRef.

Lennon, C. L., 1975: LDAR-A new lightning detection and ranging system. Eos, Trans. Amer. Geophys. Union, 56, 991.

Maggio, C., and Coauthors, 2005: Lightning initiation locations as a remote sensing tool of large thunderstorm electric field vectors. J. Atmos. Oceanic Technol., 22, 1059-1068, CrossRef.

Maier, L. M., C. Lennon, T. Britt, and S. Schaefer, 1995: Lightning Detection and Ranging (LDAR) system performance analysis. Preprints, Sixth Conf. on Aviation Weather Systems, Dallas, TX, Amer. Meteor. Soc., 305-309.

McCaul, E. W., Jr., J. Bailey, J. Hall, S. J. Goodman, R. J. Blakeslee, and D. E. Buechler, 2005: A flash clustering algorithm for North Alabama Lightning Mapping Array data. Preprints, Conf. on Meteorological Applications of Lightning Data, San Diego, CA, Amer. Meteor. Soc., 5.2. [Available online at https://ams.confex.com/ams/Annual2005/techprogram/ paper 84373.htm]

McCaul, E. W, Jr._, S. J. Goodman, K. M. LaCasse, and D. J. Cecil, 2009: Forecasting lightning threat using cloud-resolving model simulations. Wea. Forecasting, 24, 709-729, CrossRef.

Murphy, M. J., 2006: When flash algorithms go bad. 1st International Lightning Meteorology Conference, 2627 April 2006, Tucson, AZ, 6 pp. [Available online at http://www.vaisala.com/en/events/ildcilmc/Documents/ When\%20Flash\%20Algorithms\%20Go\%20Bad.pdf]

Proctor, D. E., 1971: A hyperbolic system for obtaining VHF radio pictures of lightning. J. Geophys. Res., 76, 1478-1489, CrossRef.

Proctor, D. E., 1981: VHF radio pictures of cloud flashes. J. Geophys. Res., 86(C5), 4041-4071, CrossRef.

Prentice, R. A., 2010: Aviation Weather Services Handbook: Federal Aviation Administration and National Weather Service. New York, NY: Skyhorse Pub., 2010. Print 388 pgs.

Rison, W., R. J. Thomas, P. R. Krehbiel, T. Hamlin, and J. Harlin, 1999: A GPS-based three-dimensional lightning mapping system: Initial observations in central New Mexico. Geophys. Res. Lett., 26, 3573-3576. [Available for purchase online at http://onlinelibrary.wiley.com/ doi/10.1029/1999GL010856/full]

Said, R. K., U. S. Inan, and K. L. Cummins, 2010: Long-range lightning geolocation using a VLF radio atmospheric waveform bank. J. Geophys. Res., 115, D23108, CrossRef.

Simpson, J., R. F. Adler, and G. R. North, 1988: A proposed Tropical Rainfall Measuring Mission (TRMM) satellite. Bull. Amer. Meteor. Soc., 69, 278-295, CrossRef.
Sloop, C. D., C. Liu, and S. Heckman, 2014: Analysis of Earth Networks total lightning detection efficiency versus LIS for 2011 through 2013 in North America. 18th Conf. IOAS-AOLS, Amer. Meteor. Soc., Atlanta, GA, 17-21 Jan. [Available online at https://ams.confex.com/ ams/94Annual/webprogram/Paper239080.html]

Stano, G. T., K. K. Fuell, and G. J. Jedlovec, 2010: NASA SPoRT GOES-R Proving Ground Activities. 6th Symposium on Future National Operational Environmental Satellite Systems-NPOESS and GOES-R, Amer. Meteor. Soc., Atlanta, GA, 17-21 Jan. 10, 8 pp. [Available online at https://ams.confex.com/ ams/90annual/techprogram/paper 163879.htm]

Stano, G. T. , K. K. Fuell , and G. J. Jedlovec 2011: Improved real-time lightning trend products. 5 th Conf. on Meteorological Applications of Lightning Data, Amer. Meteor. Soc., Seattle, WA, 23-27 Jan 11, 8.1, 8pp. [Available online at https://ams.confex.com/ ams/91Annual/webprogram/Paper182136.html]

Stano, G. T. _ and B. Carcione, 2012: Evaluation of NASA SPoRT's pseudo-Geostationary Lightning Mapper products in the 2011 Spring Program. 8th Symposium on Future Operational Environmental Satellites, Amer. Meteor. Soc., New Orleans, LA, 22-26 Jan 12, $6 \mathrm{pp}$. [Available online at https://ams.confex. com/ams/92Annual/webprogram/Paper203352.html]

Stano, G. T., _, C. J. Schultz, L. D. Carey, D. R. MacGorman, and K. M. Calhoun, 2014: Total Lightning observations and tools for the 20 May 2013 Moore, Oklahoma supercell. J. Operational Meteor., 2, 77-88, $\underline{\text { CrossRef. }}$

Sweers, G. and J. Gokcen, 2012: Lightning strikes: protection, inspection, and repair. Aero Magazine, 48, 19-28. [Available online at http://www.boeing.com/commercial/ aeromagazine/articles/2012 q4/pdfs/AERO 2012q4 article4.pdf]

Thomas, R. J., P. R. Krehbiel, W. Rison, S. J. Hunyady, W. P. Winn, T. Hamlin, and J. Harlin, 2004: Accuracy of the Lightning Mapping Array. $J$. Geophys. Res., 109, D14207, CrossRef.

Christian, H. J., R. J. Blakeslee, and S. J. Goodman, 1992: Lightning Imaging Sensor for the Earth Observing System. Tech. Rep. NASA TM-4350, NASA, Washington, D.C. 